\title{
Clinical features and risk factors of angiography headache and evaluation of its relationship to primary headaches
}

\author{
Turgay Demir ${ }^{1}$, Hasan Bilen Onan ${ }^{2}$, Mehmet Balal $^{1}$, Erol Aksungur ${ }^{2}$, Sebnem Bicakci ${ }^{1}$ \\ ${ }^{1}$ Department of Neurology, Cukurova University, School of Medicine, Adana, Turkey \\ ${ }^{2}$ Department of Radiology, Cukurova University, School of Medicine, Adana, Turkey
}

\begin{abstract}
Introduction. Angiography headache is defined as a new headache caused directly by cerebral angiography. We aimed to investigate the prevalence and clinical characteristics of angiography headache, and its relationship with primary headaches.

Material and methods. This single-centre prospective cohort study was carried out in our tertiary healthcare centre. Patients who had undergone a diagnostic cerebral angiography procedure between March 2016 and June 2017 were included in the study. During and after the procedure, we evaluated the patients in terms of occurrence of headache, and, if present, details about time to onset of headache after cerebral angiography, duration of headache, accompanying symptoms (nausea, vomiting, photophobia and phonophobia), and degree and severity of pain.
\end{abstract}

Results. A total of 226 patients were included in the study. The prevalence of angiography headache was found to be $22.1 \%$ $(n=50)$. While angiography headache started in the first six hours in $92 \%(n=46)$ of the patients, it started after 24 hours of the angiography procedure in only $4 \%(n=2)$. Compressive headache was the most common type, described by $64 \%$ of the patients, whereas $4 \%$ of the patients described pricking or stabbing sensations. Angiography headache was associated with female gender, higher educational level, and a history of primary headache.

Conclusion. Angiography headache is an important clinical entity that must be considered during and after angiography. Experiencing angiography headache is more common among patients with a history of primary headache.

Key words: angiography headache, cerebral angiography, clinical characteristics, digital subtraction angiography, primary headache (Neurol Neurochir Pol 2019; 53 (6): 442-448)

\section{Introduction}

Digital subtraction angiography (DSA) is an extremely important invasive method used frequently for the diagnosis, treatment and follow-up of cerebrovascular diseases. However, various complications such as intracerebral haemorrhage, ischaemic stroke, angina pectoris, seizures, headache, inguinal haematoma, pneumonia, retroperitoneal haemorrhage, femoral arteriovenous fistula, and contrast-induced complications can occur after DSA. Headache after cerebral angiography is defined as an "angiography headache (AH)" under the topic "Headache attributed to other acute intracranial arterial disorder" in section 6.7.2 of the third edition of the International Classification of Headache Disorders (ICHD-3). Accordingly, $\mathrm{AH}$ is described as a new headache caused directly by cerebral angiography in cases where the headache meets at least two of the following criteria: 1) Headache developing during or within 24 hours of angiography procedure; 2) resolves within 72 hours after the end of angiography; and 3) manifests as one of the following: a) developing during contrast injection and lasts for $<1$ hour; b) developing a few hours after the angiography and lasting $>24$ hours; c) occurs in a patient with migraine and having the features of 1.1 Migraine without aura or 1.2 Migraine with aura [1].

Numerous studies have been conducted to evaluate the headaches associated with endovascular procedures as well as the effects of non-ruptured aneurysms or non-haemorrhagic arteriovenous malformations (AVMs) on headache [2-6]. However, studies evaluating the relationship between DSA and headache have been limited. 
This study aimed to determine the prevalence, risk factors, and clinical characteristics of $\mathrm{AH}$, and its relationship with primary headaches.

\section{Material and methods}

This single-centre prospective cohort study was carried out in our tertiary healthcare centre in Adana, Turkey after obtaining the approval of the local ethics committee (Cukurova University, Faculty of Medicine, Ethics Committee for Non-invasive Clinical Research -Decision No: 78-2016). The standard practices in our centre facilitated the study: experienced interventional neuroradiologists regularly perform DSA for the diagnosis and treatment of cerebrovascular diseases. After the procedure, patients are followed in the neurology clinic or in the day-patient clinic for at least 12 hours. Patients are discharged if they develop no major complications. If a major complication such as AH develops, patients are observed in the neurology clinic for at least 24 hours.

\section{Participants}

Patients who had undergone a diagnostic DSA procedure between March 2016 and June 2017 were included in the study provided they were aged $\geq 18$ years, conscious, mentally and cognitively normal, and had given written informed consent. In addition, patients with carotid or vertebral artery stenosis identified by DSA but who had not undergone endovascular treatment were also included.

Study exclusion criteria were: having been diagnosed with intracranial mass, intracranial haemorrhage (primary intracerebral haemorrhage, subarachnoid haemorrhage (SAH)), acute ischaemic stroke, intracranial aneurysm, AVM, disorders of consciousness, aphasia, moderate-to-severe dementia, and mental retardation.

\section{Data collection}

Information regarding the history of neurological diseases (e.g. epilepsy, Parkinson's disease, demyelinating diseases, neuromuscular disease), alcohol consumption, smoking, body-mass index (BMI), hypertension, diabetes mellitus (DM), hyperlipidemia, and history of head trauma (and the typical symptoms, if any) before DSA was recorded. The details about duration of radiation exposure during DSA, total radiation dose received, amount of radiation to the body surface area $\left(\mathrm{dose} / \mathrm{m}^{2}\right)$, blood pressure before and after the procedure, as well as pulse rate, respiratory rate, and oxygen saturation (by pulse oximeter) were also recorded.

\section{Monitoring protocol for angiography headache}

A temporary increase in body temperature can occur after contrast substance injection. This is known as 'flushing' and can involve the head and the face. All patients were informed about this probable situation so as to help distinguish a potential $\mathrm{AH}$ from this phenomenon. During and after the procedure, we evaluated the patients in terms of the occurrence of headache and, if present, details about time to onset of headache after DSA, duration of headache, accompanying symptoms (nausea, vomiting, photophobia and phonophobia), and the degree and severity of pain. A visual analogue scale (VAS) was used to assess the severity of headache. All patients were evaluated for the development of $\mathrm{AH}$ within the first 72 hours. Those discharged before 72 hours were contacted by phone.

\section{Angiography procedure}

DSA procedure was performed in all patients using the same angiography device (Artis zee biplane, Siemens Healthcare, Forchheim, Germany) by an experienced interventional neuroradiologist after preparing appropriate sterile packs and the access site. For local anaesthesia, a prilocaine $2 \%$ injectable solution was used in all patients. The main femoral artery (preferably the right femoral artery, the left if the right was not available) was accessed using a $5 \mathrm{Fr}$ femoral introducer. All patients underwent a standard cerebral angiography procedure where iopromide $370 \mathrm{mg} / \mathrm{mL}$ (Ultravist 370 , Schering) was used as the opaque substance. We performed arcus aortography and bilateral selective carotid, cerebral and vertebral angiography procedures. The entire cerebral venous system was visualised. After the procedure, the introducer was removed and tight compression was applied. Patients who had been immobilised for six hours were monitored and followed in the neurology clinic. Using the exam protocol software available on the post-treatment angiography device, total radiation exposure was recorded as the radiation dose per square metre of body surface area.

\section{Statistical analysis}

Statistical analyses of data were performed using IBM SPSS for Windows software (Version 20.0, IBM, Armonk, NY, USA). Categorical variables were presented as number and percentages, whereas continuous variables were presented as mean and standard deviation. Chi-square test was used for the comparison of categorical variables between the groups. Comparison of continuous variables between the groups was done by Student's t-test. Statistical significance was predetermined to be $\mathrm{p}<0.05$ for all tests.

\section{Results}

\section{Participants}

A total of 226 patients were included in the study. The frequency of $\mathrm{AH}$ was found to be $22.1 \%(\mathrm{n}=50)$. There was an equal gender distribution (50.9\% females). However, $\mathrm{AH}$ was more prevalent in females $(27 \%$ vs $17.1 \%)(\mathrm{p}=0.007)$. The mean age of the patients was $57.2 \pm 13.32$ years (range 18-82), and it was lower in the patients with AH (53.02 $\pm 12.21)$ compared to the patients without $\mathrm{AH}(58.39 \pm 13.41)$ $(\mathrm{p}=0.007)($ Tab. 1). 


\section{Relevant pre-DSA history}

Educational status was directly correlated to the frequency of AH. While most of the illiterate patients did not report AH ( $92.3 \%$ were asymptomatic), many secondary school graduates complained about AH (32.7\% were symptomatic) (Tab. 1).

The most common comorbidity was hypertension (61.5\%). By contrast, only $4 \%$ had a history of neurological diseases including Parkinson's disease $(n=4)$, epilepsy $(n=4)$ and polyneuropathy $(n=1)$. Only two of these patients developed $\mathrm{AH}$; no significant relationship was determined between $\mathrm{AH}$ and the presence of history of stroke and primary neurological diseases other than primary headache. Overall, $26.9 \%(n=61)$ of the participants reported primary headache diagnosed before DSA, and $\mathrm{AH}$ was found to be more frequent in these patients compared to those without primary headache ( $40 \%$ vs $18.2 \%$; p $=0.01)$. Of the patients with $\mathrm{AH}, 32 \%(\mathrm{n}=16)$ had tension-type headache and $8 \%(n=4)$ had migraine before DSA (Tab. 1).

Presentation of angiography headache

The vital signs of the patients with and without headache were compared before and after the DSA procedure. Heart rate was significantly lower before the procedure in those with headache, but there was no significant difference in terms of other vital signs. In addition, duration of radiation exposure, total amount of radiation, and amount of radiation to body surface area $\left(\right.$ dose $\left./ \mathrm{m}^{2}\right)$ were not significantly different between patients with $\mathrm{AH}$ and non-AH patients (Tab. 2).

While AH started in the first six hours in $92 \%(n=46)$ of the patients, it started after 24 hours of the DSA procedure in only $4 \%(n=2)$. Compressive headache was the most common type described by $64 \%$ of the patients, whereas $4 \%$ of the patients described pricking or stabbing sensations. Twenty-six percent $(n=13)$ of the patients with AH had accompanying symptoms (nausea in eight, photophobia in five, phonophobia in five and vomiting in four). Duration of headache was less than six hours in $90 \%$ and less than three hours in $78 \%$ of the patients. None of the patients reported a headache lasting longer than 24 hours. The percentages of the patients with bilateral and unilateral headache were $76 \%$ and $24 \%$, respectively. Orbito-frontal region was the most common localisation, whereas the least common was the cervical region. With regard to the severity of pain, the mean

Table 1. Demographic characteristics, comorbidities and medical history

\begin{tabular}{|c|c|c|c|c|}
\hline & $\begin{array}{c}\text { AH } \\
(n=50)\end{array}$ & $\begin{array}{c}\text { Non-AH } \\
(n=176) \\
n(\%)\end{array}$ & $\begin{array}{c}\text { Total } \\
(n=226)\end{array}$ & P-value \\
\hline Age [years] (mean \pm SD) & $53.02 \pm 12.21$ & $58.39 \pm 13.41$ & $57.2 \pm 13.32$ & 0.007 \\
\hline \multicolumn{5}{|l|}{ Gender } \\
\hline Female & $31(27)$ & $84(73)$ & $115(50.9)$ & \multirow[t]{2}{*}{0.08} \\
\hline Male & $19(17.1)$ & $92(82.9)$ & $111(49.1)$ & \\
\hline \multicolumn{5}{|l|}{ Educational status } \\
\hline Illiterate & $2(7.7)$ & $24(92.3)$ & $26(11.5)$ & \multirow{4}{*}{0.08} \\
\hline Primary & $28(20.7)$ & $107(79.2)$ & $135(59.7)$ & \\
\hline Secondary & $16(32.7)$ & $33(67.3)$ & $49(21.7)$ & \\
\hline University & $4(25)$ & $12(75)$ & $16(7.1)$ & \\
\hline \multicolumn{5}{|l|}{ Business life } \\
\hline Actively working & $16(19.5)$ & $66(80.5)$ & $82(36.3)$ & \multirow[t]{2}{*}{0.5} \\
\hline Not working & $34(23.6)$ & $110(76.4)$ & $144(63.7)$ & \\
\hline \multicolumn{5}{|l|}{ Comorbidities } \\
\hline $\mathrm{BMI}\left[\mathrm{kg} / \mathrm{m}^{2}\right]($ mean $\pm \mathrm{SD})$ & $27.48 \pm 4.68$ & $28.25 \pm 5.17$ & $28.07 \pm 5.07$ & 0.34 \\
\hline HTN & $30(21.6)$ & $109(61.9)$ & $139(61.5)$ & 0.87 \\
\hline DM & $10(15.4)$ & $55(31.3)$ & $65(28.8)$ & 0.15 \\
\hline Hyperlipidemia & $17(26.2)$ & $48(27.3)$ & $65(28.8)$ & 0.35 \\
\hline Stroke history & $17(34)$ & $53(30.3)$ & $70(31)$ & 0.6 \\
\hline Head trauma history & $8(16)$ & $14(8)$ & $22(9.7)$ & 0.09 \\
\hline Currently smoking & $16(24.2)$ & $50(28.4)$ & $66(29.2)$ & 0.6 \\
\hline Alcohol consumption & $2(4)$ & $10(5.7)$ & $12(5.3)$ & 0.6 \\
\hline Neurological disease & $2(4)$ & $7(4)$ & $9(4)$ & 0.9 \\
\hline Primary headache & $20(40)$ & $30(18.2)$ & $50(22.1)$ & 0.01 \\
\hline
\end{tabular}

$\mathrm{AH}$ - angiography headache; BMI — body mass index; DM — diabetes mellitus; $\mathrm{HTN}$ - hypertension; $\mathrm{SD}$ - standard deviation 
Table 2. Comparison of patients with and without $\mathrm{AH}$ in terms of vital signs and radiation exposure before DSA

\begin{tabular}{|c|c|c|c|c|}
\hline & $\begin{array}{c}\text { Total } \\
(n=226)\end{array}$ & $\begin{array}{c}\text { AH } \\
(n=50) \\
\text { mean } \pm \text { SD }\end{array}$ & $\begin{array}{c}\text { Non-AH } \\
(n=176)\end{array}$ & P-value \\
\hline \multicolumn{5}{|l|}{ Vital signs before DSA } \\
\hline $\mathrm{SBP}[\mathrm{mmHg}]$ & $150.53 \pm 26.88$ & $146.36 \pm 29.45$ & $151.73 \pm 26.07$ & 0.21 \\
\hline $\mathrm{DBP}[\mathrm{mmHg}]$ & $84.78 \pm 13.75$ & $82.22 \pm 12.13$ & $85.51 \pm 14.12$ & 0.13 \\
\hline Pulse [min] & $79.52 \pm 12.8$ & $76.52 \pm 10.09$ & $80.38 \pm 13.37$ & 0.01 \\
\hline Respiratory rate & $19.26 \pm 2.35$ & $19.38 \pm 2.04$ & $19.23 \pm 2.43$ & 0.65 \\
\hline Oxygen saturation [\%] & $97.42 \pm 1.56$ & $97.22 \pm 1.6$ & $97.49 \pm 1.55$ & 0.28 \\
\hline Fever $[0 C]$ & $36.19 \pm 0.27$ & $36.16 \pm 0.26$ & $36.2 \pm 0.28$ & 0.34 \\
\hline \multicolumn{5}{|l|}{ Radiation exposure } \\
\hline Radiation exposure time [min] & $8.49 \pm 5.3$ & $9.1 \pm 7$ & $8.29 \pm 4.64$ & 0.48 \\
\hline Total radiation dosage $[\mu \mathrm{Gy}]$ & $666.4 \pm 265.7$ & $697.8 \pm 283.1$ & $656.6 \pm 256$ & 0.47 \\
\hline Amount of radiation in body surface area $[\mu \mathrm{Gy} / \mathrm{m} 2]$ & $10,639.2 \pm 4,947.5$ & $\begin{array}{c}10,651.9 \pm \\
5,174.1\end{array}$ & $\begin{array}{c}10,625.4 \pm \\
4,877.6\end{array}$ & 0.98 \\
\hline
\end{tabular}

$\mathrm{AH}$ - angiography headache; DBP — diastolic blood pressure; DSA — digital subtraction angiography; SBP — sistolic blood pressure; SD — standard deviation

VAS score was $5.36 \pm 1.87$, with headache severity defined usually as moderate (Tab. 3).

\section{Angiography headache and previous primary headache}

The mean age of patients with $\mathrm{AH}$ and migraine was 44 \pm 9.81 years (range 35-56), whereas the mean age of patients with $\mathrm{AH}$ and tension-type headache was $59.12 \pm 8.49$ years (range 45-72) $(\mathrm{p}=0.006)$.

Of the 61 patients with a diagnosis of primary headache, $32.8 \%$ developed AH. However, there was no significant relationship in these patients between $\mathrm{AH}$ and gender, diabetes mellitus, hypertension, hyperlipidemia, history of stroke, neurological disease other than primary headache, stroke, alcohol consumption, smoking, blood pressure, pulse rate, respiratory rate, presence of fever before DSA procedure, oxygen saturation, or radiation dose per square metre of body surface. Development of $\mathrm{AH}$ was associated with duration of radiation exposure $(\mathrm{p}=0.04)$. Patients with a history of primary headache who developed $\mathrm{AH}$ had lower body mass index, higher educational level, and head trauma history more often than patients without $\mathrm{AH}$, but the difference was not statistically significant (Tab. 4).

\section{Discussion}

In this study, the frequency of AH was $22.1 \%$, which is consistent with the wide range of frequencies $(0.3-51 \%)$ reported in earlier studies [7-9]. Although Heiserman et al. [8] reported a relatively low rate of headache $(0.3 \%)$ in the first six hours after DSA procedure in a sample of 1,000 patients, they did not evaluate $\mathrm{AH}$ in detail, only the neurological complications. The incidence of AH was $30.2 \%$ in a case-control study performed by Aktan et al. [10] in 139 patients, whereas it was much higher $(55.6 \%)$ in a retrospective study conducted by Kwon et al. [11]. The differences between these studies in terms of the frequency of $\mathrm{AH}$ might result from methodological (patient characteristics) differences or from the inclusion of patients with intracerebral aneurysm or $\mathrm{SAH}$, which we excluded.

History of headache before the procedure, female gender, cerebrovascular disease and educational status have all been reported to be risk factors for developing $\mathrm{AH}[7,12,13]$. In our study, female gender, educational status, and history of primary headache were associated with $\mathrm{AH}$. $\mathrm{AH}$ was more prevalent in the females in our cohort $(27 \%$ vs $17.1 \%, \mathrm{p}=0.08)$, which is consistent with findings reported by Kwon et al. [11] and with the results of the study conducted by Gil-Gouveia et al. [7], who reported female gender to be a risk factor for $\mathrm{AH}$. Lower awareness about headache in patients with a lower educational level might explain the finding of the association between higher education and $\mathrm{AH}$.

The mechanism of developing AH remains unclear despite the fact that hormones, vasoactive substance (e.g. nitric oxide or serotonin) release induced by catheter placement or contrast substances, or mechanically stressed veins in individuals with a sensitive trigeminovascular nociceptive system have all been deemed responsible $[7,8,12,14]$.

In our study, the characteristics of AH were as follows: it started in the first six hours after the DSA procedure in $92 \%$, was compressive and moderate in $64 \%$ and bilateral in $76 \%$, and had accompanying symptoms such as nausea, vomiting, photophobia and phonophobia in 26\%. Aktan et al. [10] identified two types of headache starting either during or after the procedure. In the former, the headache starts immediately after the administration of the contrast substance and lasts no longer than 30 minutes. It is also associated with the sensation 
Table 3. Clinical characteristics of angiography headache

\begin{tabular}{|c|c|}
\hline Characteristics & $\begin{array}{l}\text { Angiography headache } \\
\qquad \begin{array}{c}(n=50) \\
n(\%)\end{array}\end{array}$ \\
\hline VAS score (mean \pm SD) & $5.36 \pm 1.87(2-10)$ \\
\hline \multicolumn{2}{|l|}{ Headache starting time } \\
\hline During procedure & $10(20 \%)$ \\
\hline First hour & $17(34 \%)$ \\
\hline $1-6$ hours & $19(38 \%)$ \\
\hline $6-24$ hours & $2(4 \%)$ \\
\hline After 24 hours & $2(4 \%)$ \\
\hline \multicolumn{2}{|l|}{ Pain character } \\
\hline Compressive & $32(64 \%)$ \\
\hline Throbbing & $9(18 \%)$ \\
\hline Stinging-burning & $9(18 \%)$ \\
\hline \multicolumn{2}{|c|}{ Accompanying symptoms } \\
\hline Nausea & $8(16 \%)$ \\
\hline Vomiting & $4(8 \%)$ \\
\hline Photophobia & $5(10 \%)$ \\
\hline Phonophobia & $5(10 \%)$ \\
\hline \multicolumn{2}{|c|}{ Headache duration (hours) } \\
\hline$<1$ & $24(48 \%)$ \\
\hline $1-3$ & $21(42 \%)$ \\
\hline $6-12$ & $3(6 \%)$ \\
\hline $12-24$ & $2(4 \%)$ \\
\hline$>24$ & $0(0 \%)$ \\
\hline \multicolumn{2}{|l|}{ Lateralisation } \\
\hline Bilaterally & $38(76 \%)$ \\
\hline Unilaterally & $12(24 \%)$ \\
\hline Right & $7(14 \%)$ \\
\hline Left & $5(10 \%)$ \\
\hline \multicolumn{2}{|l|}{ Location } \\
\hline Orbito-frontal & $19(38 \%)$ \\
\hline Temporo-parietal & $13(26 \%)$ \\
\hline Parieto-occipital & $18(36 \%)$ \\
\hline Cervical & $3(6 \%)$ \\
\hline
\end{tabular}

SD - standard deviation;VAS — visual analogue scale

of pressure or pulsatile character with no accompanying symptoms (i.e. nausea, vomiting, photophobia or phonophobia). In the latter, headache occurs in the first 24 hours after the procedure. It usually develops 2-10 hours after DSA, disappears within three hours of onset, shows a bilateral fronto-temporal or a generalised localisation, is of mild-moderate severity, and has a pulsatile character.

This second type of $\mathrm{AH}$ has been reported to be more prevalent in patients with a history of primary headache; in the present study, this type of headache occurred in the first six hours in $92 \%$ of cases and was more frequently associated with bilateral localisation and moderate severity [10]. However, most of our patients had tension-type headache, and migraine headache was less common.

We concluded that this may be associated with the higher mean age of AH patients with a history of tension-type headache compared to those with a history of migraine, particularly females. A history of primary headache is associated with $\mathrm{AH}$, as has been reported in earlier studies [7, 10-12].

Most studies in the literature have emphasised that $\mathrm{AH}$ is common in those with primary headache. Literature studies evaluating $\mathrm{AH}$ in detail in patients with primary headache are few. The present study is the first to evaluate $\mathrm{AH}$ in patients with primary headache. Education, BMI, history of head trauma, and duration of radiation exposure were found to play a critical role in the development of $\mathrm{AH}$ in patients with primary headache. The prevalence of AH may be associated with a low pain threshold in patients with primary headache and higher education. The prolonged duration of DSA procedure also increases the duration of radiation exposure. Patient stress is also increased with prolonged duration of DSA procedure. The duration of radiation exposure might be associated with increased stress, which is high in patients with $\mathrm{AH}$.

According to the ICHD-3, AH needs to be more diffuse, severe and migrainous in patients with migraine [1]. Of the 61 patients with a history of primary headache, $29.5 \%$ $(n=18)$ had a history of migraine and only $22.2 \%(n=4)$ of these patients developed AH. Our patients typically described $\mathrm{AH}$ as a tension-type headache with diffuse localisation. $\mathrm{AH}$ was defined as migrainous in two of these patients. Sixteen patients, who had been previously diagnosed with tension-type headache, developed AH. In contrast to the literature, we therefore showed that $\mathrm{AH}$ is more likely to occur in patients having tension-type headache before DSA, and that the $\mathrm{AH}$ itself is likely to manifest as a tension-type headache. This is probably associated with the anxiety and stress experienced by the patients before the procedure, which is confirmed by increased blood pressure prior to the procedure determined even in the patients without documented hypertension. However, the headache described by these patients after the procedure did not have the characteristics of a typical hypertensive vascular headache. Such headaches also did not occur in patients with high blood pressure before, during or after the procedure who developed $\mathrm{AH}$.

The ICHD- 3 defines the headache associated with radiation as "headache attributed to radiosurgery of the brain" [1]. However, no published study has evaluated the relationship between radiation and headache in patients who had undergone DSA. This indicates that the present study is the first to evaluate such a relationship.

We determined that there was no significant relationship between the occurrence of $\mathrm{AH}$ and radiation dose to the head, duration of radiation exposure, total radiation dose, or radiation dose to body surface area. 
Table 4. Comparison of patients with $\mathrm{PH}$ in terms of $\mathrm{AH}$

\begin{tabular}{|c|c|c|c|c|}
\hline & $\begin{array}{c}\text { AH } \\
(n=20)\end{array}$ & $\begin{array}{l}\text { Non-AH } \\
(n=41) \\
n(\%)\end{array}$ & $\begin{array}{c}\text { Total } \\
(n=61)\end{array}$ & P-value \\
\hline \multicolumn{5}{|l|}{ Type of PH } \\
\hline Migraine & $4(21.1)$ & $15(36.6)$ & $19(31.1)$ & \\
\hline Tension-type headache & $16(38.1)$ & $26(63.4)$ & $42(68.9)$ & \\
\hline \multicolumn{5}{|l|}{ Gender } \\
\hline Female & $9(39.1)$ & $14(60.9)$ & $23(37.7)$ & 0.41 \\
\hline Male & $11(28.9)$ & $27(71.1)$ & $38(62.3)$ & \\
\hline $\mathrm{BMI}^{*}\left[\mathrm{~kg} / \mathrm{m}^{2}\right]$ & $26.43 \pm 3.99$ & $28.61 \pm 5.25$ & & 0.07 \\
\hline \multicolumn{5}{|l|}{ Educational status } \\
\hline Illiterate & $0(0)$ & $8(100)$ & $8(13.1)$ & 0.08 \\
\hline Primary & $11(40.7)$ & $16(59.3)$ & $27(44.3)$ & \\
\hline Elementary & $3(50)$ & $3(50)$ & $6(9.8)$ & \\
\hline High school & $5(33.3)$ & $10(66.7)$ & $15(24.6)$ & \\
\hline University & $1(20)$ & $4(80)$ & $5(8.2)$ & \\
\hline History of head trauma & $6(30)$ & $4(9.8)$ & $43(67.2)$ & 0.06 \\
\hline \multicolumn{5}{|l|}{ Frequency of PH attacks } \\
\hline$>4$ & $10(47.6)$ & $11(52.4)$ & $21(34.4)$ & 0.35 \\
\hline $3-4$ & $3(27.3)$ & $8(72.7)$ & $11(18)$ & \\
\hline $1-2$ & $5(22.7)$ & $17(77.3)$ & $22(36.1)$ & \\
\hline$<1$ & $2(28.6)$ & $5(71.4)$ & $7(11.5)$ & \\
\hline Prophylactic treatment of $\mathrm{PH}$ & $5(38.5)$ & $8(61.5)$ & $13(21.3)$ & 0.74 \\
\hline $\begin{array}{l}\text { Duration of radiation [min] } \\
\text { (mean } \pm \mathrm{SD})\end{array}$ & $9.8 \pm 7.3$ & $6.25 \pm 3.51$ & & 0.04 \\
\hline
\end{tabular}

$\mathrm{AH}$ - angiography headache; $\mathrm{BMI}$ - body mass index; $\mathrm{PH}$ - primary headache; $\mathrm{SD}$ - standard deviation

The relationship between pre-DSA vital signs and developing $\mathrm{AH}$ has not been previously evaluated. In the present study, we showed that there is a relationship between the development of $\mathrm{AH}$ and either a low pulse rate or a history of headache before the procedure. To date, most studies about AH have considered only the headaches that occurred during or after the endovascular procedures. Some of these studies considered patients with aneurysm or AVM in the SAH group, or considered patients with stenosis in the carotid/vertebral artery stenosis group.

By contrast, in the present study, we excluded patients with SAH, AVM, aneurysm and carotid or vertebral artery stents because headaches due to intracerebral haemorrhage or due to an endovascular procedure could interfere with the presentation of $\mathrm{AH}$.

In addition, symptomatic headaches that develop during angiography should also be kept in mind. Symptomatic headaches due to situations such as vasodilatation of meningeal arteries, posterior reversible encephalopathy syndrome, and also cerebral hyperperfusion syndrome after carotid interventions, have been reported in the literature [15-17].

\section{Conclusions}

$\mathrm{AH}$ is an important clinical entity that must be considered during and after DSA. However, we found distinct and novel characteristics indicating that $\mathrm{AH}$ is associated with moderate severity, compressive character, and duration of less than six hours. Experiencing AH is more common among patients with a history of primary headache. Studies on this topic, and the classifications, remain inadequate in evaluating some clinical pictures. It would be beneficial to set up better structured studies with larger patient series based on the current data.

Conflicts of interest. There are no conflicts of interest.

Financial support and sponsorship. None.

Informed Consent. Informed consent was obtained from all participants in the study.

\section{References}

1. Headache Classification Committee of the International Headache Society (IHS). The International Classification of Headache Disorders, 
3rd edition (beta version). Cephalalgia. 2013; 33(9): 629-808, doi: 10.1177/0333102413485658, indexed in Pubmed: 23771276.

2. Agostoni E, Zagaria M, Longoni M. Headache in subarachnoid hemorrhage and headache attributed to intracranial endovascular procedures. Neurol Sci. 2015; 36 Suppl 1: 67-70, doi: 10.1007/s10072-0152193-2, indexed in Pubmed: 26017515.

3. Ji W, Liu A, Yang $X$, et al. Incidence and predictors of headache relief after endovascular treatment in patients with unruptured intracranial aneurysms. Interv Neuroradiol. 2017; 23(1): 18-27, doi: 10.1177/1591019916666503, indexed in Pubmed: 27609752.

4. Esmanhotto BB, Piovesan EJ, Lange MC. Brazilian experience of the influence of endovascular treatment on headache in patients with ruptured intracranial aneurysms. Acta Neurol Scand. 2017; 135(3): 377-381, doi: 10.1111/ane.12595, indexed in Pubmed: 27061104.

5. Qureshi Al, Suri MF, Kim SH, et al. Effect of endovascular treatment on headaches in patients with unruptured intracranial aneurysms. Headache. 2003; 43(10): 1090-1096, doi: 10.1046/j.1526-4610.2003.03211.x, indexed in Pubmed: 14629245.

6. Ellis JA, Mejia Munne JC, Lavine SD, et al. Arteriovenous malformations and headache. J Clin Neurosci. 2016; 23: 38-43, doi: 10.1016/j. jocn.2015.08.003, indexed in Pubmed: 26461909.

7. Gil-Gouveia RS, Sousa RF, Lopes L, et al. Post-angiography headaches. J Headache Pain. 2008; 9(5): 327-330, doi: 10.1007/s10194-0080057-3, indexed in Pubmed: 18668198.

8. Heiserman JE, Dean BL, Hodak JA, et al. Neurologic complications of cerebral angiography. AJNR Am J Neuroradiol. 1994; 15(8): 1401-7; discussion 1408, indexed in Pubmed: 7985557.

9. Ramadan NM, Gilkey SJ, Mitchell M, et al. Postangiography headache. Headache. 1995; 35: 21-24.
10. Aktan Ç, Özgür Ö, Sindel T, et al. Characteristics of headache during and after digital substraction angiography: A critical re-appraisal of the ICHD-3 criteria. Cephalalgia. 2017; 37(11): 10741081, doi: $10.1177 / 0333102416665878$, indexed in Pubmed: 27558501.

11. Kwon MA, Hong CK, Joo JY, et al. Headache After Cerebral Angiography: Frequency, Predisposing Factors, and Predictors of Recovery. J Neuroimaging. 2016; 26(1): 89-94, doi: 10.1111/jon.12290, indexed in Pubmed: 26331267.

12. Gil-Gouveia R, Fernandes Sousa R, Lopes L, et al. Headaches during angiography and endovascular procedures. J Neurol. 2007; 254(5): 591-596, doi: 10.1007/s00415-006-0330-9, indexed in Pubmed: 17415512.

13. Rasmussen BK, Olesen J. Symptomatic and nonsymptomatic headaches in a general population. Neurology. 1992; 42(6): 1225-1231, doi: 10.1212/wnl.42.6.1225, indexed in Pubmed: 1603351.

14. Silberstein SD. Sex hormones and headache. Revue Neurologique (Paris). 2000; 156(suppl): S30-S41.

15. Kremer S, Grand S, Dananchet $Y$, et al. MRI during postangiography headache. Neurology. 2002; 58(9): 1425, doi: 10.1212/wnl.58.9.1425, indexed in Pubmed: 12011298.

16. Das B, Goel G, Mahajan A, et al. An Unusual Cause of Posterior Reversible Encephalopathy Syndrome. Asian J Neurosurg. 2018; 13(4): 1254-1256, doi: 10.4103/ajns.AJNS_188_17, indexed in Pubmed: 30459910.

17. van Mook WN, Rennenberg RJ, Schurink GW, et al. Cerebral hyperperfusion syndrome. Lancet Neurol. 2005; 4(12): 877-888, doi: 10.1016/S1474-4422(05)70251-9, indexed in Pubmed: 16297845. 